\title{
Effects of Column Length and Particle Diameter on Phospholipid Analysis by Nanoflow Liquid Chromatography-Electrospray Ionization-Mass Spectrometry
}

\author{
Ju Yong Lee, Sangsoo Lim, and Myeong Hee Moon ${ }^{\#}$ \\ Department of Chemistry Yonsei University Seoul, 120-749 South Korea
}

Received September 6, 2011; Revised September 14, 2011; Accepted September 14, 2011

First published on the web September 15, 2011; http://dx.doi.org/10.5478/MSL.2011.2.3.065

\begin{abstract}
The effects of column length and particle size on the efficiency of separation and characterization of phospholipids (PLs) are investigated using nanoflow liquid chromatography-electrospray ionization-tandem mass spectrometry (nLC-ESI-MS-MS). Since PLs are associated with cell proliferation, apoptosis, and signal transduction, it is of increasing interests in lipidomics to establish reliable analytical methods for the qualitative and quantitative profiling of PLs related to biomarker development in adult diseases. Due to the complexity of PLs, the preliminary separation of PLs is necessary prior to MS analysis. In this study, length of capillary column and the particle size of reversed phase $\left(\mathrm{C}_{18}\right)$ packing materials are varied to find a reliable condition for the high speed and high resolution separation using $8 \mathrm{PL}$ standard mixtures. From experiments, it was found that a capillary column of nLC-ESI-MS-MS analysis for PL mixtures can be minimized to a $5 \mathrm{~cm}$ long pulled tip column packed with $3 \mu \mathrm{m} \mathrm{C}_{18}$ particles without losing resolution.
\end{abstract}

Key words: phospholipids, nLC-ESI-MS-MS, effect of column length, particle size, capillary column

\section{Introduction}

Phospholipids (PLs) are major components of cellular wall and key molecules in signal transduction, cell proliferation and death. ${ }^{1,2}$ Because of the potential as candidate biomarkers in adult diseases, ${ }^{3,4}$ PLs and lysophospholipids (LPLs) are of increasing interests in lipidomics. However, analysis of these complicated lipid groups is not quite straightforward since PLs and LPLs are varied in different polar head groups, different lengths and unsaturation degree of acyl chain. Recent advances in electrospray ionization-mass spectrometry (ESI-MS) enable one to characterize the molecular structure of lipid species with high sensitivity and speed, ${ }^{5,6,7}$ however a preliminary separation of complicated mixture of PLs from biological samples such as plasma, urine, and cells is still required to reduce ionization suppression caused by spectral congestion. Chromatographic methods have been hyphenated with MS to analyze PLs: gas chromatography-mass spectrometry (GC-MS), ${ }^{8}$ thin layer chromatography (TLC) with matrixassisted laser desorption and ionization time-of-flight mass spectrometry (MALDI-TOFMS), ${ }^{9}$ and high performance liquid chromatography with ESI-MS (HPLC-ESI-MS). ${ }^{10}$ Recently, reversed phase nanoflow LC-ESI-MS-MS has shown its capability in simultaneous separation and structural identification of complicated PL and LPL mixtures from human urine or blood plasma samples. ${ }^{11,12,13,14,15}$ It was reported that the limit

*Reprint requests to Dr. Myeong Hee Moon

E-mail:mhmoon@yonsei.ac.kr of detection (LOD) can be lowered to 2.2 fmol of phosphatidylcholine (PC) by nLC-ESI-MS experiments. ${ }^{16}$ However, use of a typical capillary column $(75 \mu \mathrm{m}$ i.d. $\times$ $15 \mathrm{~cm}$ ) even with gradient elution often requires an hour of separation along with substantial increase in system pressure.

In this study, the effect of capillary column dimensions on efficiency of separation and characterization of PLs and LPLs has been examined by reducing the column lengths and diameter of packing resins in nLC-ESI-MS-MS experiments. The purpose of this study was to evaluate the efficiency of columns with reduced dimensions for improved separation speed without losing resolution and incurring system pressure. Experiments were focused to examine the resolution of separation and experimental plate number of few standard PL species at the positive ion mode of nLC-ESI-MS-MS.

\section{Materials and Methods}

Phosphatidylcholine (PC) and phosphatidylethanolamine (PE) standards examined in this study were $16: 0$-LPC, $18: 0$-LPE, $12: 0 / 12: 0$-PC, $12: 0-12: 0$-PE, $14: 0 / 14: 0$-PC, $14: 0 / 14: 0$-PE, $16: 0 / 16: 0-\mathrm{PE}$, and $18: 0 / 18: 0-\mathrm{PC}$ purchased from Avanti Polar Lipids Inc. (Alabaster, AL, USA). All solvents $\left(\mathrm{CH}_{3} \mathrm{CN}\right.$, isopropanol, $\mathrm{CH}_{3} \mathrm{OH}$, water) used for $\mathrm{LC}$ mobile phase were HPLC grade from Avantor Performance Materials (Phillipsburg, NJ, USA). The capillary columns were prepared in our laboratory by packing capillary tubes (75 $\mu$ m-i.d., $360 \mu$ m-o.d. Polymicro Technology LLC, Phoenix, AZ, USA) with Magic $\mathrm{C}_{18}, 5 \mu \mathrm{m}$ or $3 \mu \mathrm{m}, 100 \AA$ (Michrom Bioscience Inc, Auburn, CA, USA) resin by varying lengths 
from 15 to 10 and $5 \mathrm{~cm}$. Before packing, one end of capillary tube was pulled by flame to make a tip. The detailed packing procedure for a pulled tip capillary column can be found from previous reports. ${ }^{13,14,15}$ For nLC-ESI-MS-MS experiments, a model 1200 pump system from Agilent Technologies (Palo Alto, CA, USA) equipped with an autosampler and an LTQ Velos ion trap mass spectrometer (Thermo Finnigan, San Jose, CA, USA) were utilized. The capillary column was connected with pump via a PEEK MicroCross (Upchurch Scientific, Oak Harbor, WA, USA) in which capillary tubes from the pump, capillary column, a Pt wire for ESI voltage, and vent tube were all connected. Between MicroCross and capillary column, an in-line microfilter from Upchurch Scientific was placed to protect the packing materials in column from back flowing to the MicroCross.

For gradient elution, mobile phase solutions used were 10/90 (v/v) $\mathrm{CH}_{3} \mathrm{CN} /$ water for $\mathrm{A}$ and 20/20/60 (v/v) $\mathrm{CH}_{3} \mathrm{CN} /$ $\mathrm{CH}_{3} \mathrm{OH} /$ isopropanol for $\mathrm{B}$. Both were added with $0.1 \%$ (v/v) formic acid for positive ion mode. During sample loading, the vent tube was closed by an on-off valve located at the end of the tube and mobile phase A was utilized at $500 \mathrm{~nL} / \mathrm{min}$. After sample loading (14 min), pump was set at $7 \mu \mathrm{L} / \mathrm{min}$ with the on-off valve open to allow the pump flow to be split just before the column inlet in order to reduce dwell time during gradient elution. Flow rate for the analytical column was set to be $500 \mathrm{~nL} / \mathrm{min}$ during gradient elution. After $14 \mathrm{~min}$ of sample loading period, mobile phase B jumped to $80 \%$ in $1 \mathrm{~min}$ and then ramped to $100 \% \mathrm{~B}$ during $35 \mathrm{~min}$, and maintained at $100 \%$ for $20 \mathrm{~min}$. Then mobile phase B returned to $0 \%$ in $1 \mathrm{~min}$ and stayed for $20 \mathrm{~min}$ for column reconditioning before a next injection.

ESI voltage of $3.0 \mathrm{kV}$ was applied under $250^{\circ} \mathrm{C}$ of capillary temperature and the normalized collision energy for data dependent MS-MS analysis was set at 45\% (positive ion mode). MS range was 450-800 for the MS scan. Data dependent MS-MS analysis was carried out for the first three prominent ions in sequence for each MS scan. Injection amount was 1 pmol of each PL and LPL standard.

\section{Results and Discussion}

The effects of column length and particle diameter on the efficiency of separation were investigated by using 1 LPC, 1LPE, 3PC and 3PE standard species in columns packed with $\mathrm{C}_{18}$ resins of two different particle diameters and with varying lengths $(15,10$, and $5 \mathrm{~cm})$. Figure 1 shows the base peak chromatograms (BPCs) of nLC-ESI-MS runs obtained from columns packed with resins of a) $d_{p}=5 \mu \mathrm{m}$ and $b$ )

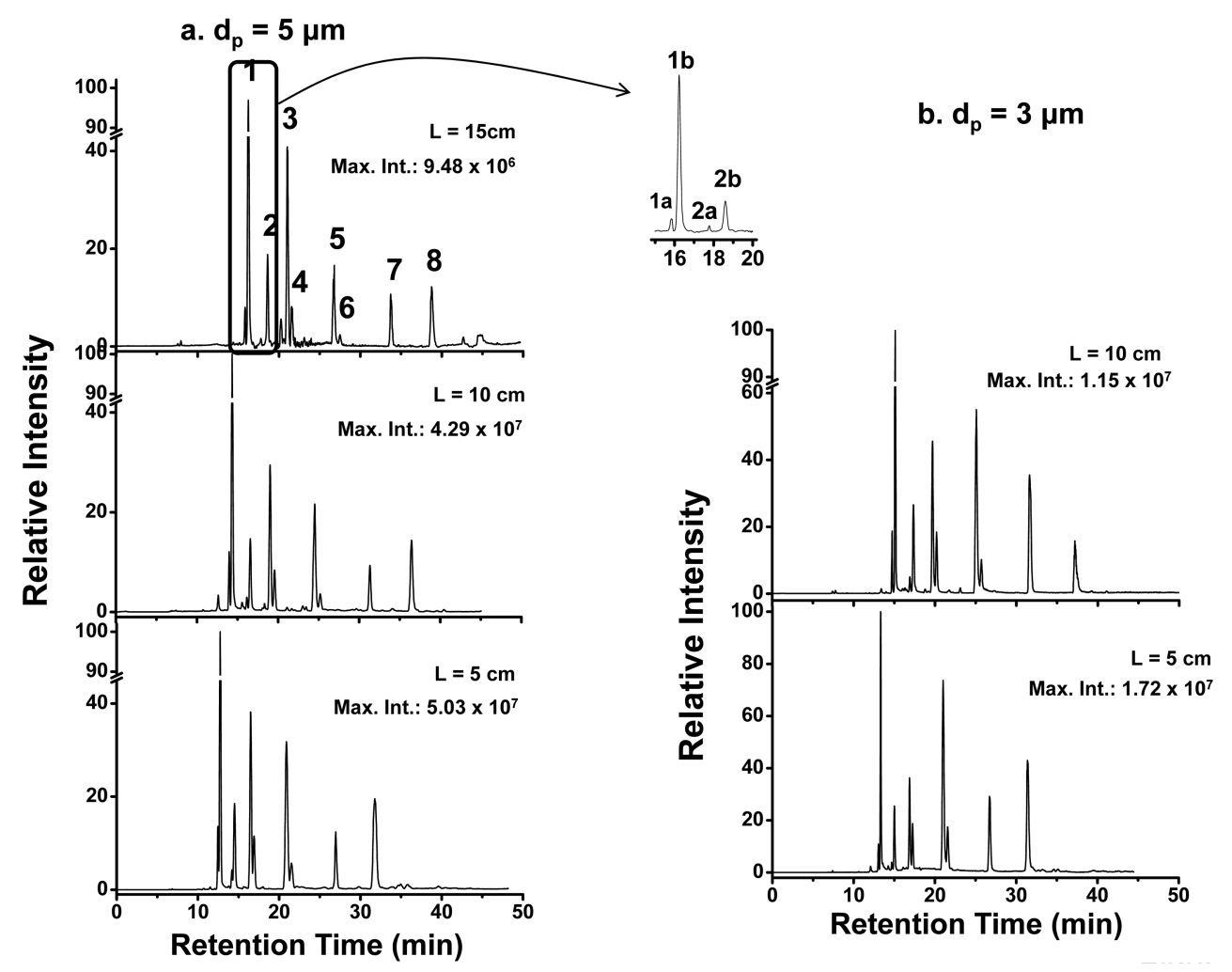

Figure 1. Base peak chromatograms (BPCs) of eight PL \& LPL standards (1: $16: 0$-LPC, 2: 18:0-LPE, 3: $12: 0 / 12: 0$-PC, 4: 12:0$12: 0$-PE, $5: 14: 0 / 14: 0$-PC, $6: 14: 0 / 14: 0$-PE, $7: 16: 0 / 16: 0$-PE. $8: 18: 0 / 18: 0$-PC) by nLC-ESI-MS-MS using capillary columns (75 $\mu$ m-i.d. and $360 \mu \mathrm{m}$-o.d.) packed with $\mathrm{C} 18$ resins of a) $d_{p}=5 \mu \mathrm{m}$ and b) $d_{p}=3 \mu \mathrm{m}$ with different lengths. Enlarged chromatogram of peaks 1 and 2 represent the regioisomers of $16: 0$-LPC and $18: 0$-LPE; 1a: lyso/16:0-PC, 1b: 16:0/lyso-PC, 2a: lyso/18:0-PE, and 2b: $18: 0 / l y s o-P E$. 
$\mathrm{d}_{\mathrm{p}}=3 \mu \mathrm{m}$ at different column lengths, L, marked in each chromatogram using a gradient elution condition described in experimental section. In the top BPC of Figure 1(a), PC and $\mathrm{PE}$ standards elute in a decreasing order of polarity (PC followed by $\mathrm{PE}$ ) and of a chain length (shorter acyl chain first). LPC and LPE elute earlier than PC's and PE's, respectively, since LPLs are less hydrophobic than PLs due to the loss of one acyl chain. The peak 1 (16:0-LPC) in the top BPC of Figure 1(a) appears with the two separated peaks marked as $1 \mathrm{a}$ and $1 \mathrm{~b}$ in the enlarged chromatogram which are identified as regioisomers differing by the position of the acyl chain attached to the glycerol carbon of phospholipids. For 16 : 0-LPC standard molecules, peaks $1 \mathrm{a}$ and $1 \mathrm{~b}$ are identified as lyso/16:0-PC and 16:0/lyso-PC, respectively. The notation lyso/16:0-PC refers to a PC molecule in which the acyl chain at the sn- 1 carbon of glycerol is replaced by hydroxyl group. The relative intensity of the two regioisomers appears with the latter peak (16:0/ lyso-PC) more abundantly. The molecular structure of these regioisomers can be distinguished by fragment ion spectra in Figure 2 obtained by data dependent collision induced dissociation (CID) experiment during nLC-ESI-MS-MS. Figure 2 shows the CID spectra of 1 a (observed $\mathrm{m} / \mathrm{z}$ 496.6) and $1 \mathrm{~b}$ molecules. Both CID spectra show the same four

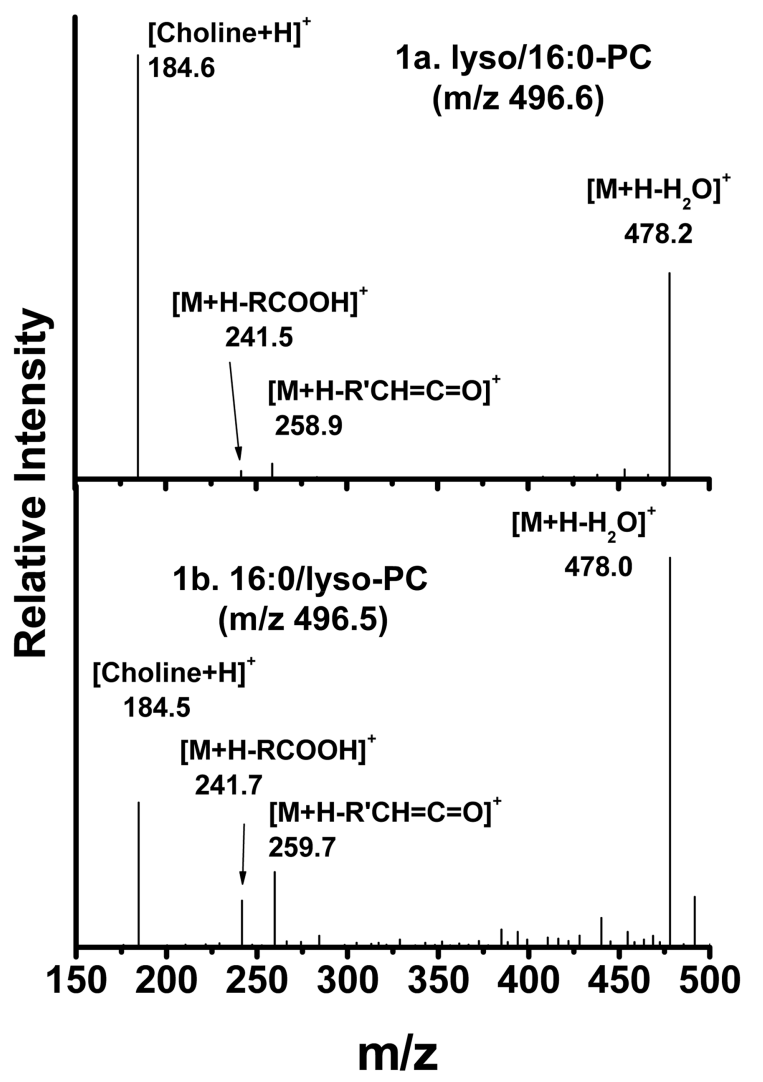

Figure 2. Fragment ion spectra of regioisomers of $16: 0$-LPC obtained by data dependent CID experiment of nLC-ESI-MS-MS. characteristic fragment ions: $\mathrm{m} / \mathrm{z} 184.6$ from the phosphocholine cation $\left(\mathrm{H}_{2} \mathrm{PO}_{4}\left(\mathrm{CH}_{2}\right)_{2} \mathrm{~N}\left(\mathrm{CH}_{3}\right)_{3}, 184 \mathrm{amu}\right)$ which is an important indicator to imply the presence of a choline head group, $\mathrm{m} / \mathrm{z}$ $478.2\left[\mathrm{M}+\mathrm{H}-\mathrm{H}_{2} \mathrm{O}\right]^{+}$after the loss of water molecule from the parent ion, and $\mathrm{m} / \mathrm{z} 241.5$ and 258.9 from the neutral loss of a fatty acid in the form of carboxylic acid $\left([\mathrm{M}+\mathrm{H}-\mathrm{RCOOH}]^{+}\right)$ and ketene $\left(\left[\mathrm{M}+\mathrm{H}-\mathrm{R}^{\prime} \mathrm{CH}=\mathrm{C}=\mathrm{O}\right]^{+}\right)$, respectively. However, the difference between the two spectra is the relative ratio of intensity of the phosphocholine cation and $\left[\mathrm{M}+\mathrm{H}-\mathrm{H}_{2} \mathrm{O}\right]^{+}$. Apparently, the fragment ion intensity of the water dissociated parent ion is relatively large for the $16: 0 /$ lyso-PC molecule. The relative difference in retention time of regioisomers can be expected from the different interactions in which hydrophobic interaction between $\mathrm{C}_{18}$ and acyl chain becomes stronger with the regioisomer having an acyl chain attached to sn-1 carbon due to the extended molecular geometry. Therefore, from the CID spectra along with the different retention time in nLC-ESI-MS-MS, regioisomers of LPC and LPE can be identified with molecular structures.

This study utilizes a relatively high flow rate $(500 \mathrm{~nL} / \mathrm{min})$ to achieve maximum separation speed while typical flow rates utilized in pulled tip capillary columns were $200 \sim 300 \mathrm{~nL} / \mathrm{min}$. When the column length decreases as shown in Figure 1(a) $\left(\mathrm{d}_{\mathrm{p}}=5 \mu \mathrm{m}\right)$, retention times of PC and PE species decrease to some degree but with a considerable increase of MS peak intensity. About $17 \%$ decrease in retention time from $\mathrm{L}=15$ to $5 \mathrm{~cm}$ results in $6 \%$ decrease in experimental plate number (N) measured from the peak $5(14: 0 / 14: 0-\mathrm{PC})$ as listed in Table 1 . When separation resolution $\left(\mathrm{R}_{\mathrm{s}}\right)$ values are evaluated for the two nearby eluting species (peaks $5: 14: 0 / 14: 0-\mathrm{PC}$ and $6: 14: 0 / 14: 0-\mathrm{PE}$ ), it showed that there is $10 \%$ decrease in resolution between 15 and $5 \mathrm{~cm}$ columns. Apparently, effects of column length and particle diameter on the separation of PL standards are not significant in performance in this work due to the use of gradient elution. However the system pressure is greatly reduced to 81 bar from 362 bar when the column length reduces to $5 \mathrm{~cm}$. To overcome the decreased efficiency of separation, the same C18 packing materials of reduced diameters, $d_{p}=3 \mu \mathrm{m}$, is packed in columns of two different lengths in Figure 1(b). The column with $\mathrm{L}=15 \mathrm{~cm}$ exhibits a high pressure inoperable with the current HPLC system. With the $L=10 \mathrm{~cm}$ column, the measured $R_{s}$ value for the peaks 5 and 6 is the highest $(0.86 \pm 0.07)$ among the five run conditions as well as with the largest $\mathrm{N}$ value $(=79,400)$.

Table 1. Measured resolution (Rs) of the separation of \# 5 $(14: 0 / 14: 0-\mathrm{PC})$ and \# $6(14: 0 / 14: 0-\mathrm{PE})$, plate number $(\mathrm{N})$ of peak 5 , and column pressure at each column dimension during nLC-ESI-MS.

\begin{tabular}{cccccc}
\hline \hline $\mathrm{d}_{\mathrm{p}}(\mu \mathrm{m})$ & \multicolumn{3}{c}{5} & \multicolumn{2}{c}{3} \\
\hline $\mathrm{L}(\mathrm{cm})$ & 15 & 10 & 5 & 10 & 5 \\
\hline $\mathrm{Rs}$ & $0.84 \pm 0.08$ & $0.80 \pm 0.09$ & $0.76 \pm 0.08$ & $0.86 \pm 0.06$ & $0.82 \pm 0.09$ \\
$\mathrm{~N}$ & 73,646 & 71,759 & 69,657 & 79,368 & 72,809 \\
$\mathrm{P}_{\max }$ (bar) & 362 & 155 & 81 & 331 & 194 \\
\hline
\end{tabular}

Mass Spectrom. Lett. 2011 Vol. 2, No. 3, 65-68 
However, the system pressure ramps to the level similar to that of $\mathrm{L}=15 \mathrm{~cm}$ with $\mathrm{d}=5 \mu \mathrm{m}$. When the column length reduces to $L=5 \mathrm{~cm}$ with $\mathrm{d}_{\mathrm{p}}=3 \mu \mathrm{m}$, resolution $\left(\mathrm{R}_{\mathrm{s}}=0.82 \pm\right.$ $0.09)$ and plate number $(\mathrm{N}=72,800)$ are similar to those observed with $L=15 \mathrm{~cm}$ with $d_{p}=5 \mu \mathrm{m}$, however, the entire separation time is reduced with the decrease of pressure which is reasonable to work without incurring a significant back pressure. By comparing the MS signal intensities of the highly retained component (peak 8) between the two extreme column conditions, it shows that peak intensity is significantly increased to $6.9 \times 10^{6}$ from $9.5 \times 10^{5}$. From this study, it is found that a short capillary column $(\mathrm{L}=5 \mathrm{~cm}$, $\mathrm{d}_{\mathrm{p}}=3 \mu \mathrm{m}$ ) performs better than a typical capillary column dimension $\left(\mathrm{L}=15 \mathrm{~cm}, \mathrm{~d}_{\mathrm{p}}=5 \mu \mathrm{m}\right)$ for $\mathrm{nLC}$-ESI-MS-MS analysis of phospholipids.

\section{Conclusions}

This study demonstrates the effects of column length and particle size on the efficiency of separation of phospholipids by nanoflow LC-ESI-MS-MS. High resolution separation of complicated PL mixtures from biological sample is essential prior to MS analysis due to the ionization suppression effect of low abundant molecules. In general, reducing particle size in LC enhances separation capability, however increased column pressure along with the increased analysis time needs to be compromised with the maximally allowed backpressure. The data obtained from this study shows that increase in column pressure from the decrease of particle size to $3 \mu \mathrm{m}$ from $5 \mu \mathrm{m}$ can be compensated with the reduction of column length to $5 \mathrm{~cm}$ from $15 \mathrm{~cm}$ and it results with enhancement of separation speed without losing resolution and column efficiency, which will be conducive to analyze complicated PL \& LPL mixtures from biological samples.

\section{Acknowledgements}

This study was supported by grant NRF-2011-0016438 and in part by grant NRF-2010-0002021 from the National Research Foundation of Korea.

\section{References}

1. Brouwers, J. F. H. M.; Vernooji, E. A. A. M.; Tielens, A. G. M.; van Golde, L. M. G. J. Lipid Res. 1999, 40, 164.

2. Wright, M. M.; Howe, A. G.; Zaremberg, V. Biochem. Cell Biol. 2004, 82, 18.

3. Williams, C. M.; Maunder, K. Eur. J. Clin. Nutr. 1993, 47, 260.

4. Sutphen, R.; Xu, Y.; Wilbanks, G. D.; Fiorica, J.; Grendys, E. C.; Jr. LaPolla, J. P.; Arango, H.; Hoffman, M. S.; Martino, M.; Wakeley, K.; Griffin, D.; Blanco, R. W.; Cantor, A. B.; Xiao, Y. J.; Krischer, J. P. Cancer Epidemiol. Biomarkers Prev. 2004, 13,1185.

5. Hsu, F. F.; Turk, J. J. Am. Soc. Mass Spectrom. 2001, 12,1036

6. Hsu, F. F.; Turk, J. J. Am. Soc. Mass Spectrom. 2001, 11, 986.

7. Han, X.; Gross, R. W. J. Am. Soc. Mass Spectrom. 1995, 6, 1202.

8. Heller, D. N.; Murphy, C. M.; Cotter, R. J.; Fenselau, C.; Uy, O. M. Anal. Chem. 1988, 60, 2787.

9. Rohlfing, A.; Muthing, J.; Pojlentz, G.; Distler, I.; PeterKatalinc, J.; Berkenkamp, S.; Dreisewerd, K. Anal. Chem. 2007, 79, 5793.

10. Kim, H. Y.; Wang, T. C. L.; Ma, Y. C. Anal. Chem. 1994, 66, 3977.

11. Taguchi, R.; Houjou, T.; Nakanishi, H.; Yamazaki, T.; Ishida, M.; Imagawa, M.; Shimizu, T. J. Chromatogr. B 2005, $823,26$.

12. Bang, D. Y.; Kang, D.; Moon, M. H. J. Chromatogr. A 2006, 1104, 222.

13. Kim, H.; Min, H.K.; Kong, G; Moon, M. H. Anal. Bioanal. Chem. 2009, 393, 1649.

14. Min, H. K.; Kong, G.; Moon, M. H. Anal. Bioanal. Chem. 2010, 396, 1273.

15. Lee, J. Y.; Min, H. K.; Moon, M. H. Anal. Bioanal. Chem. 2011, 400, 2953.

16. Ahn, E.; Kim, H.; Chung, B. C.; Moon, M. H. J. Separation Sci. 2007, 30, 2598. 